\title{
EXPLORING AUSTRALIAN UNDERGRADUATE PRE-REGISTRATION NURSING CURRICULA: WHERE DO SCIENCE SUBJECTS FIT?
}

\author{
Patricia A. Logan \\ School of Biomedical Science \\ Charles Sturt University, Wagga Wagga, Australia \\ plogan@csu.edu.au \\ Lyndall Angel \\ Faculty of Science \\ Charles Sturt University, Wagga Wagga, Australia \\ langel@csu.edu.au
}

\begin{abstract}
Despite several attempts to define what foundational science is required by and for the nursing profession, uncertainty has long existed in this area. Several attempts have been undertaken to elicit the appropriate level and depth of foundational science with the only clear result being that science has been recognised as key to good practice. The aim of this research was to review the amount of science content in pre-registration curricula and explore how science was incorporated into educational programs. Two sets of data were obtained: approved curriculum documents supplied by universities, and public university website course subject information. Heads of Schools at Australian universities teaching pre-registration Nursing were invited to provide approved curriculum documents in 2007 and again in 2014. The 2007 documents demonstrated diverse approaches with no convergence towards one theory, philosophy or teaching strategy. In 2014, a clear move to flexible, online, case-based or inquiry learning and simulations strategies was observed. The volume of science was calculated by determining the proportion of science content based on credit point allocations to subjects for all publicly available course descriptions in 2006 and 2012. This calculation was also undertaken for the nine matched 2007 and 2014 volunteered curriculum documents. Results indicate a decrease in overt science content between 2006 and 2012. However, there is evidence of an increase in science content integration into nursing subjects in the 2012 and 2014 documentation.
\end{abstract}

\section{Keywords}

Bioscience, nursing, science curriculum, pre-registration

\section{Introduction}

The positive relationship between improved knowledge of bioscience among nurses and patient care outcomes provides evidence to support the incorporation of science into undergraduate nursing curricula (Jordan \& Hughes, 1998; Prowse \& Heath, 2005; Prowse \& Lyne, 2002). The study reported here examines Australian university subject lists, abstracts and curriculum documentation, to 
review how and to what extent science subjects are incorporated into the written curricula for pre-registration nursing education. Science subjects are defined as including anatomy, physiology, microbiology, and the foundational aspects of chemistry and physics which support learning in human biology, pharmacology and pathophysiology.

To ensure that graduates are eligible for national registration, programs are designed to meet the standards for pre-registration nurse education prescribed by the Australian Nursing \& Midwifery Accreditation Council (ANMAC, 2012). These guidelines give no indication of necessary content other than that it "comprehensively addresses the National Competency Standards for the Registered Nurse ... best practice perspectives on nursing ... and emerging national and regional health priorities" (p. 14). As of June 2013, this document supersedes the previous versions of the guidelines of the Australian Nurses and Midwives Council (ANMC) - (the Accreditation Guidelines (2009)), which were approved by the National Nurse and Midwives Board (NNMB) in February 2010. The ANMC document stated that "the central focus should be on nursing and contemporary nursing practice" (p. 27) so that students can meet national competency requirements. That document had only one statement with respect to science-based content; science content had to be sufficient to support pharmacology and medication management (p. 13). Individual state registration guidelines that preceded the NNMB guidelines indicated that human bioscience subjects should be included to support clinical practice subjects, but detail to support this statement was lacking (Logan, 2008).

Furthermore, it has been proposed that the presentation of a multiplicity of professional theoretical approaches in student programs may reveal conflicting worldviews and may result in increased student anxiety (Logan, 2008) and, potentially, a rejection of program content (Jegede \& Aikenhead, 1999). Freshwater (2000) claimed that education based on a hegemonic philosophy which is unsympathetic to the discipline being taught will generate student frustration with that discipline. An exploration of curricula and subject descriptions to demonstrate how nursing educators view the incorporation of science content within the chosen pedagogies, and their relationship with nursing theories, could be expected to inform science educators of nursing students' needs.

Concerns over the science content of nursing programs have been expressed. Brown and Seddon (1996) estimated the proportion of science in nursing programs in the United Kingdom in 1993 to be $21 \%$. In 2006, as part of a PhD project, Logan (2008) estimated the explicit science content of Australian programs using website information. The exercise resulted in questions of how science content was incorporated into nursing so that, in 2007, she collected nursing curriculum documents to examine the descriptions of underlying nursing theories and pedagogies supporting the curriculum frameworks. In this study, the estimation of science content was repeated in 2012 using website information, and 
in 2014 university schools of nursing were again asked to share their approved curriculum documentation for comparison.

\section{Background to science education in nursing}

Studies to determine the level and depth of science being taught to nursing students have a long history with one of the earliest formal studies being undertaken in the UK (see Wilson, 1975). However, stereotypical views of nursing as "hands-on-care" persist, with students in a recent U.K. study reporting that they thought the academic load and the complexity of knowledge required was much higher than was needed for the actual work (O'Donnell, 2011). In contrast, $81 \%$ of New Zealand students felt that sufficient bioscience was incorporated in their nursing course (Friedel \& Treagust, 2005). The challenge for nursing students in learning any biology-related science is that it draws from many science sub-disciplines, and consequently requires the student to possess an appropriate level of scientific understanding to cope with the complexity in order to develop inductive and inferential reasoning skills (Donald, 2002). The ability to create mental abstractions in science is important for the retention of scientific information (Donald, 2002).

The majority of Australian programs provide science classes in a service-taught mode (i.e. taught by a school other than the nursing school) rather than integrated into nursing subjects (Logan, 2008). The curriculum for these subjects is usually developed in a consultative manner based upon nurse teachers' perceived requirements. However, Minasian-Batmanian, Lingard and Prosser (2006) found that students perceive service-taught subjects as "tools" to be stored for later application, rather than deliberately integrating this knowledge into their other subjects. This approach can reinforce the perception of a theory-practice dichotomy. In addition, it has been claimed that the rapid increase in detailed scientific knowledge of the last few decades has made it increasingly difficult to identify just what foundational knowledge is required to support practice (Estabrooks et al., 2005). Regular course reviews are recognised as contributing to an increase in the material to be covered (Arthur \& Baumann, 1996) and most programs undergo revision on a five-year cycle (van de Mortel \& Bird, 2010).

There have been calls to "re-envision" nursing since its incorporation into the university sector (Giddens \& Brady, 2007). These have been based on the disparate backgrounds of the entering students, or content saturation and additive curriculum (Giddens \& Brady, 2007), and/or issues related to attrition (Andrew et al., 2008). Student attrition in pre-registration nursing programs was estimated at 24.5\% (10 universities in Queensland: range 9.7 - 41.8\%) (Gaynor et al., 2006), which is a slight improvement on the 1994 Australian national estimate of $27 \%$ (Harvey \& McMurray, 1994). Bioscience subjects are recognised as causing nursing students the most anxiety (Andrew, 2002), and as a major reason for student drop-out (Andrew et al., 2008). Perceptions of the lack of content relevance to practice appear to contribute to students' anxiety levels (Jordan, Davis, \& Green, 1999; McVicar, 2009; Thornton, 1997); it has been noted that 
despite nursing students perceiving pharmacology modules as the most relevant, they also found them the most challenging (Jordan et al., 1999; Manias \& Bullock, 2002). This is an indication that relevance to practice, of itself, is not enough to lessen study-associated anxiety.

Exposure to professional practice before learning the theory has been suggested in order to alleviate the theory-practice gap tension (Jordan \& Hughes, 1998; McVicar, 2009). However, nursing students' understanding of bioscience material has not been shown to benefit from previous experience in health care settings (O’Donnell, 2011; Salamonson, Andrew \& Everett, 2009; Whyte, Madigan, \& Drinkwater, 2011) unlike other areas of health science practice such as paramedicine (Whyte et al., 2011). Bradley, Blackshaw and Nolan (2006) found that nurse lecturers had variable levels of bioscience knowledge and thus lacked the confidence to integrate foundational science into their teaching. In their observational study of nursing practice, Estabrooks et al. (2005) found that, despite the recognition that pre-practice foundational knowledge was important, it alone was insufficient to support practice. This is reinforced by the study reported by Davis (2010) where $40.5 \%$ of Registered Nurses (RN) $(n=42)$ claimed that their undergraduate human bioscience studies did not prepare them for postregistration training. A qualitative study by McVicar, Clancy and Mayes (2010) confirmed that most nurses viewed their science knowledge as "weak." How this impacted on their confidence to practise was not raised in that study although there have been several attempts at determining the role of science in practice (see, for example, Prowse \& Heath, 2005; Prowse \& Lyne, 2002). However, students in preceptor relations have reported that their understanding of complex care was greatly influenced by their perception of the RN's level of expertise (Stockhausen, 2005), and potentially inhibited their ability to connect theory to practice.

Nursing students' pre-entry perceptions of nursing (Logan, 2008), their varied educational backgrounds (Dwyer \& Higgs, 1999; Heath, 2002; Logan, Cox, \& Nielsen, 2013) and the range of ages from 17-68 (Gaynor et al., 2006; Logan et al., 2013) suggest that adult learning approaches should not be assumed as the most appropriate. The bionursing model proposed by Akinsaya and Hayward (1980) was intended to provide explicit links between nursing practice and life science theories, but there are no reports of it being implemented and tested.

To overcome the shortcomings of traditional teaching, Problem-based Learning (PBL) has been implemented in nursing education (Bebb \& Pittam, 2004; Don, 2001; Turner, Davies, Beattie, Vickerstaff, \& Wilkinson, 2006). However, PBL programs have not consistently incorporated foundational science content (Logan, 2008). Integration of all discipline areas requires clear PBL curriculum design (Turner et al., 2006) and provides the opportunity not only to provide relevance to practice, but also to delineate discipline approaches, whilst integrating foundational knowledge. Don (2001) maintained that a PBL approach not only engaged the students but removed their sense of being overwhelmed by the science material. PBL is not universally agreed to be appropriate for nursing due 
to its illness-centred nature when contrasted with a framework for maintaining wellness (Bebb \& Pittam, 2004; Kocaman, Dicle, \& Ugur, 2009). Inquiry-based Learning (IBL) is similar to PBL except that it removes the focus on a problem to be solved, enabling incorporation of the exploration of wellness (Bebb \& Pittam, 2004).

Students' prior learning experiences greatly influence their success in PBL because those with well-developed problem formulation and research skills are most likely to benefit, whereas group learning can allow those without these skills to flounder and go unnoticed (Forbes, 2000; Wells, Warelow, \& Jackson, 2009). Consequently, the wide range of educational backgrounds of nursing students may hinder implementation of PBL, both from the students' and the lecturers' viewpoints. Other strategies such as case-based frameworks and narrative formats have been devised (Diekelmann, Ironside, \& Gunn, 2005) but there is no clear evidence that these approaches improve student outcomes.

The narrative framework approach takes advantage of students' life experience and stories and was specifically designed for nursing education (Diekelman, et al., 2005), and has been used as a tool to emphasise the relevance of theory to clinical practice. This has the potential to overcome the variability in students' educational backgrounds (Diekelmann et al., 2005; Ironside, 2006; McAllister, 2001;

Swenson \& Sims, 2000). While such phenomenological approaches have been criticised as risking sentimentality and lacking precision (Ironside, 2001), other situated frameworks also exist to facilitate student-centred learning such as work integrated learning (WIL) associated with clinical practice subjects.

The university curriculum documents submitted for program accreditation in this project include reference to the nursing philosophy or theory as well as the teaching framework used for the program. Many nursing philosophies and theories have been proposed for nursing practice (Tomey \& Alligood, 2005) but it has been suggested that differences between the philosophy of science, the biomedical model, and nursing discipline philosophies with their influence on teaching approaches would increase the potential for study tension and conflict in the student classroom (Logan, 2008; Logan \& Angel, 2010). Evaluation of the effectiveness of any one undergraduate degree curriculum appears only in the curriculum documents to the extent that it provides justification for the changes made since the last iteration. This is despite many publications in nursing journals, such as Nurse Education Today, outlining the benefits of specific program designs or educational frameworks.

\section{Method}

The aims of this study were to:

- identify the teaching philosophies and frameworks used by Australian universities for nursing education;

- determine the level of specific science content, and if or how that content was incorporated into the programs; and, 
- assess if and how changes have occurred over time.

The project used curriculum documents to identify existing approaches, and the alignment of subjects within these approaches. After an initial review of subject documentation available on university websites in 2006, the Heads of Australian university schools offering nursing degrees were asked in 2007 for access to curriculum documents used for accreditation. If the whole document was not available, access was requested to the sections relating to the teaching and nursing philosophical frameworks. University anonymity was preserved by numbering the documents in the order they were received, namely, U1-16. The contents were compared with the current literature to ascertain whether innovative frameworks were being incorporated into teaching programs. In 2014 Heads of Schools were again asked for access to approved curriculum documents and nine were provided.

A subject, as defined by the Australian Qualifications Framework (AQF), is an accredited single component of study within a qualification (AQF, 2011). Some universities are now naming what in Australia was traditionally named a "subject" a "course" aligning to the international term. The AQF does not give an indication of how many hours of study are associated with a single accredited unit. To facilitate transparent credit transfer, the Bologna process undertaken by the European Commission Education and Training gives one credit for each hour of study. In the United Kingdom, this translates to 4,600 hours for a three-year degree. For a nursing program, this time is allocated equally between practice and theory components (Snelling, Lipscomb, Lockyer, Yates, \& Young, 2010).

Because Australian universities have yet to set such a regulation definitively, this study used allocated credit points to determine the proportions of science content.

The course guides available on university websites in 2006 and in 2012 were used to ascertain any change in the level of science content. Subjects were identified as science subjects based on their titles and abstracts, for example: anatomy and physiology; microbiology; pathophysiology and pharmacology; bioscience. Examples of subject descriptions are provided in Table 1. The estimate of science content was calculated by determining the number of credit points dedicated to explicit science content as defined by the abstracts and titles as a proportion of the total credit points for the pre-registration program. For example, if human bioscience, pathophysiology and pharmacology subjects made up 32 credit points of a degree totalling 192 credit points, then the component of explicit science was calculated as $16.7 \%$.

Table 1

Subject description examples

\begin{tabular}{ll}
\multicolumn{1}{c}{ Title } & \multicolumn{1}{c}{ Abstract } \\
\hline Level 1 & [This subject] focuses on the anatomy and physiology of the \\
Anatomy and & normal human body. Emphasis is on the development of both \\
Physiology 1 & knowledge and understanding of a broad range of core concepts \\
& such as anatomical organisation along with chemical and physical \\
& processes and homeostatic balance. Changes through the lifespan
\end{tabular}


Level 2

Pathophysiology and Pharmacology will be discussed by taking an integrated and exploratory approach to teaching. Topics covered include introductory chemistry, cells and tissues, integument, skeletal, muscular, nervous and special senses and the endocrine systems.

[This subject] will introduce the processes of disease and injury in the human body. It builds on knowledge acquired in [pre-requisite level 1 subject]. Learning objectives include descriptions of illness trajectories, connections between structure and function of the body and processes of disease and injury; explain and articulate the logic of signs and symptoms that manifest during a disease process; explain how pharmacological interventions and contemporary practice affect pathophysiology, patient therapy and patients outcomes; pharmacokinetics and pharmacodynamics of drug interventions for the conditions listed. Topics covered are drawn from the AIHW 2011 Australian Health Priorities:

- $\quad$ arthritis and musculoskeletal conditions

- asthma

- cancer

- cardiovascular health

- diabetes mellitus

- injury prevention and control

- mental health

- obesity

\section{Results}

Universities treat curriculum documents as intellectual property and so they are not easily accessible despite it being expected by approving bodies that they are publicly available for scrutiny by stakeholders. Almost all universities who volunteered their documentation reiterated the need for confidentiality to be maintained. Each university was provided with the original summary of the University Nursing Theories and Pedagogies Table from the 2007 curriculum collection (Logan, 2008) as part of the 2014 invitation to volunteer their latest documents, demonstrating the identification system to be used for this current comparison.

Table 2 presents the proportion of science content in pre-registration nursing programs. The proportion of credit points or hours allocated to science subjects is calculated as a proportion of the total. The fourth column shows the differences between 2006 and 2012 programs, based on changes for each of the 26 universities for which paired data were available. Despite no net difference being evident over the four-year period (end 2006 to beginning 2012) for the matched pairs, the minimum increased but the maximum decreased giving a fall of four per cent in the median values. In some cases, only superficial name changes had occurred or material had been moved from one subject to another. When the original search of subject outlines was carried out in 2006, only one university had clearly incorporated all the science material into the nursing subjects through PBL. In 2012, PBL was being used by another university but only for nursing subjects. The 2012 search revealed that at least three universities now incorporate 
science into the nursing subjects. However, in the nine 2014 curriculum documents, which included one university that had previously been specific about using PBL, inquiry based (IBL) or case based strategies predominate. For the nine matched universities, there has been on average a $1.85 \%$ decrease in specific science content (see Table 3 for individual university changes).

Table 2

Explicit science subject content within pre-registration nursing programs as presented on university websites

\begin{tabular}{|c|c|c|c|}
\hline & $\begin{array}{c}\text { Explicit science } \\
\text { subject content end } \\
\mathbf{2 0 0 6}^{1}\end{array}$ & $\begin{array}{l}\text { Explicit science } \\
\text { subject content } \\
\text { beginning } 2012^{2}\end{array}$ & $\begin{array}{l}\text { Difference between } \\
2006 \text { and } 2012^{3}\end{array}$ \\
\hline Minimum & $4 \%$ & $8 \%$ & $-18 \%$ \\
\hline Maximum & $30 \%$ & $25 \%$ & $17 \%$ \\
\hline Median & $17 \%$ & $13 \%$ & $0 \%$ \\
\hline Mean & $16 \%$ & $14 \%$ & $-2 \%$ \\
\hline
\end{tabular}

Notes to Table 2.

1. 27 universities used in calculation. One university had a fully integrated program and so was not included in the calculation.

2. 27 providers included in calculation (includes 2 non-university providers). Three universities had fully integrated programs so were not included in the calculation.

3. 24 universities with matching paired data.

The same method was repeated in 2006 and 2012 to calculate the estimates providing overall trends. The calculations did not take into account those programs for which the subjects were not available and integrated programs were not included. The main limitation of the website data was its lack of curriculum detail that is generally available in a specific university's accredited program documentation. The science estimate was restricted to publically available information which may be further truncated to meet website restrictions. Individual subject descriptions (abstracts and syllabuses) were not definitive for the level of detail often giving only an overall guide to topics to be covered. Where it was indicated that content had become integrated into nursing subject abstracts, an indication of the level of integration was difficult to define and not consistent across all documentation and so cannot be estimated. Also, the use of credit point values per subject for the calculations does not reflect the hours students spend on a particular subject. Nor does it include revision aspects of moving science classroom content to nursing and practice subjects or the evidence-based practice components of those practicum and nursing theory subjects.

Table 2 indicates that the median in 2006 of $17 \%$ decreased to $13 \%$ for 2012 . These estimates are much lower than the previous 1993 UK estimate of $21 \%$ (Brown \& Seddon, 1996). Table 3 provides the change over time for the matched pairs of university documents available in 2007 and 2014 along with the educational approaches. The average change was a decrease of $1.85 \%$ for these 
nine universities with a maximum decrease of $15.6 \%$. Integration of level 2 pathophysiology and pharmacology subjects into nursing subjects is the main cause for the larger changes, for example, U1 and U16 in Table 3. The apparent overall decrease of 4\% in explicit science content between 2007 and 2012 does not give an indication of how much of that content has become incorporated into nursing subjects. Thus the values in Table 1 and 3 could be expected to be underestimates of the true amount of science included in a nursing pre-registration program.

From the 2007 documents, the theories of nursing associated with practice as a philosophy of "care" were identified and are tabulated in Table 5. The theory expressed by U6 was reminiscent of the work of Erickson's Theory of Caritative Caring (Tomey \& Alligood, 2006) although no specific reference is given in the curriculum document. "Nursing as Caring" uses story as a method of understanding nursing knowledge and the complexities of the "nursing situation," and was used in narrative pedagogy by U12 (Diekelmann et al., 2005). U4 and U5 placed science within their chosen philosophies, U5 stating that nursing is a scientific activity. Both universities espoused philosophies that acknowledge the humanistic aspect of nursing. U13 and U15 both used the nursing framework that four understandings - "nursing, person, health and environment" - are central to nursing practice. No particular theorists are given as references. In 2014, nine universities supplied their revised documents either in full or part and these are included in Table 5.

Table 3

Educational approaches from matched curriculum documents 2007 and 2014

\begin{tabular}{|c|c|c|c|}
\hline ID & $\begin{array}{l}\text { Science } \\
\text { Content } \\
\text { Change }\end{array}$ & Educational approach 2007 & Educational approach 2014 \\
\hline U1 & $-15,60 \%$ & $\begin{array}{l}\text { PBL, transformative education } \\
\& \text { solution focused teaching } \\
\text { approaches (Boud \& Felletti, } \\
\text { 1997; McAllister 2005; } \\
\text { McAllister et al., 2006) }\end{array}$ & $\begin{array}{l}\text { Constructive alignment as described by } \\
\text { Biggs \& Tang (2007). } \\
\text { E-learning, simulations and virtual world } \\
\text { formats using inquiry-based learning as } \\
\text { described by Stephenson \& Galloway, } \\
\text { 2004. Capstone subject includes an } \\
\text { EPortfolio. } \\
\text { Pathophysiology and pharmacology } \\
\text { subjects integrated into nursing clinical } \\
\text { science subjects. }\end{array}$ \\
\hline U4 & $4.20 \%$ & None specified & $\begin{array}{l}\text { Student-centred learning, technology } \\
\text { enhanced teaching, "real world" or } \\
\text { authentic contexts. } \\
\text { Blended learning, academic literacies, } \\
\text { Work Integrated Learning (WIL), first } \\
\text { year experience and capstone frameworks. } \\
\text { Provides for one elective subject. } \\
\text { Outcomes based curricula. }\end{array}$ \\
\hline U5 & $-8.30 \%$ & Outcomes based curricula. & "learning experiences that incorporate \\
\hline
\end{tabular}


U8 $-3.5 \%$

\section{U9 $\quad 6.75 \%$}

U11 $4 \%$

U16 $-4.20 \%$
Inquiry-based learning (McCalister 2001; Bebb \& Pittam 2004)

Learning communities (Duke, 2004)

None given

Student centred, interactive,

None specified - post grad entry specific for Science graduates. 2 years plus a specific nursing practice clinical workshop.

"what the student does"

(Biggs, 1999; Shuell, 1986)

Reflective learning log: "the reflective learning log is part of the assessment of each

Traditional format with distinct anatomy and practice based. nursing topic and encourages" contemporary health care research, evidence based educational approaches and identified societal needs. ...

Emphasise prevention rather cure in determining allocation of course content and resources."

Predominantly enquiry based learning. Blended and online learning.

Bevis (1998) Learning typology: item learning; directive learning; rational learning; syntactical learning; situated learning and inquiry learning. Used to “...develop various cognitive skills and demonstrate how nursing requires scientific and artistic ways of thinking about the world." Outcomes based curricula rather than objective based in order to incorporate "non-observable attributes important to nursing" such as "ability to convey sympathy."

Student centred learning, scaffolding of support and nursing inquiry - recognition that many students do not have "academic maturity ... for fully autonomous or selfdirected learning."

Uses scaffolded "problem of the week," mock panels for hypothetical situations and audience response monitors. Students encouraged to critically examine practice - their own and that of the profession.

Flexible program delivery with a choice of electives and majors e.g., rural and remote health or mental health.

Now incorporates a capstone subject. Uses simulated practice activities to integrate theory and practice.

None specified - postgraduate entry where the human anatomy and physiology prerequisite is by distance only using text book and quiz sheets and online tests.

Problem/inquiry based, scenario approach to teaching and learning throughout the curriculum; competency based approach to assessment.

Principles of adult learning, case based, authentic learning, nursing inquiry and reflection

Blended online and face-to-face; clinical simulations; virtual cases.

Simulations, "real world" problems and cased based formats. Pathophysiology 
physiology, pathophysiology subjects separated from nursing subjects. Included a subject on clinical pathology and one on nutrition across the lifespan. integrated into nursing subjects to better address provision of contexts for learning and clinical application. Introductory Pharmacology introduced as a standalone subject.

Curriculum mapped to national health priorities.

ANMAC competencies and Graduate attributes aligned.

Capability statements designed for incremental and sequential development mapped to a rubric and associated performance markers for evaluating competence - based on the work of Oliver (Teaching fellowship: benchmarking partnerships for graduate employability, Learning and Teaching Council, 2010).

Of 31 Australian universities offering nursing in 2007, 15 supplied curriculum documentation. Examination of the 2007 curriculum documents revealed that six of the university documents did not allow the identification of specific teaching approaches. The educational formats provided in these documents are summarised in Table 4. For the paired 2007 and 2014 documents this information is given in Table 3.

\section{Table 4}

Overarching program educational approach in 2007 ( $n=9$; some included more than one approach)

\begin{tabular}{lc}
\hline Pedagogy format description & $\begin{array}{c}\# \\
\text { Universities }\end{array}$ \\
\hline Androgogy & 2 \\
Student-centred learning & 1 \\
Problem Based Learning (PBL) & 2 \\
Inquiry Based Learning (IBL) & 2 \\
Transformatory & 1 \\
Phenomenological/Interpretivism (includes Narrative and Situated/Contextual) & 3 \\
Solution focused teaching & 1 \\
Social constructivism & 2 \\
"what the student does" (after Biggs (2003)) & 1 \\
Life-long learning & 2 \\
Self-directed learning & 1 \\
Learning communities & 1 \\
\hline
\end{tabular}


Table 5

Nursing theory and/or educational philosophy from matched curriculum documents 2007 and 2014

\begin{tabular}{cl}
\hline ID & $\begin{array}{l}\text { Nursing theory and/or educational } \\
\text { philosophy } 2007\end{array}$ \\
\hline U1 & Educational philosophy: \\
& "commitment to a collaborative, \\
& multidisciplinary approach and \\
& connecting theory and evidenced based \\
& practice. ... follows a health and \\
& wellness to illness continuum across the \\
& lifespan and prepares them for practice \\
& in a variety of settings. Teaching and \\
& learning are integrated with community \\
& engagement so there is reciprocal \\
& learning. ... heightened understanding of \\
& social contexts and the diverse roles for \\
& professional nurses in the broader \\
& community"
\end{tabular}

\section{U4 Nursing philosophy:}

"Nursing is both an art and a science with a unique body of knowledge that draws from the physical, behavioural and social sciences and the humanities (Crisp \& Taylor 2001)."

"[it] supports the pursuit of wellness, prevention of illness, restoration to optimal health and where necessary, the preparation of people for a dignified and peaceful death."

"In accordance with writers such as Boykin \& Schoenhofer (2001), Mayeroff (1971) and Roach (1987) it is argued that key attributes of caring to be highlighted include compassion, competence, confidence, conscience and commitment." Educational philosophy:

“... studies within the course are organised thematically as both structural and relational themes. ... 3 key themes: introduction to nursing practice, developing clinical practice, transition to professional practice. Integration between the themes occurs as a result of experience that emphasises dialogue, learning and reflection and, through these processes, theory and practice come together ... 3 relational themes underpinning studies throughout the course are inquiry, analysis and reflection."

Nursing theory and/or educational philosophy 2014

Client-centred care: "curriculum developed with the intent of focusing students on the needs of their clients, as opposed to traditional health delivery models. ... focus on health of populations across the lifespan, in order to prepare the nursing workforce for challenges associated with demographic and health care trend changes in Australia and internationally." Develop the student nurse to become a 'knowledge worker in health' as described by Antrobus (1997) who can fully participate in the multidisciplinary healthcare team. "... students need to achieve highly engaged learning at the level of applying, theorizing, and critically reflecting (Biggs \& Tang, 2007).”

Based on Bruner (1960) - The spiral curriculum (or spiral of learning) is developed as "iterative revisiting of topics"... to deepen understanding "with each successive encounter building on the previous one" (Masters \& Gibbs, 2007, pp.2/10).

im: "profile [the pass graduate] as a highly competitive, work-ready global citizen."

Curriculum based in 3 integrating themes (Kent et al., 2005): Building clinical knowledge and skills; becoming a nursing professional; collaborating for optimal outcomes. 


\begin{tabular}{ll}
\hline ID & Nursing theory and/or educational \\
philosophy 2007
\end{tabular}

U6 Nursing philosophy:

"curriculum is provided that promotes and reclaims the human -human relationship between nurse and person, lies at the heart of nursing's identity, and corrects the balance in an increasingly technical health care world." "... the work of the nurse client partnership is the essence of nursing and the focus for nursing education. The goal of this partnership is to extend the spaces currently available for healthy living. ... Healthy spaces are those that enhance the potential for a healthy body, a planet in harmony and a beautiful spirit."

\section{Educational philosophy:}

"this program will be solution-centred, and focus on exploring issues such as resilience, strengths, supports and resources that can be harnessed to

\author{
Nursing theory and/or \\ educational philosophy 2014 \\ Philosophy of person-centred caring with a \\ focus on primary health care. \\ "the essence of nursing relates to human \\ relationships with a central focus on \\ assisting individuals in transition \\ experiences across the lifespan (Meleis \& \\ Trangenstein, 1994; Schumacher \& \\ Meleis, 1994). These include: illness to \\ health and rehabilitation to recovery; \\ developmental transitions such as \\ pregnancy to parenthood; social transitions \\ such as family caregiving, death and dying \\ (Kralik, Visentin \& Van Loon, 2006; \\ Meleis, Sawyer, Im, Hilfinger-Messias \& \\ Schumacher, 2000); and incorporates the \\ role of the nurse in maintaining health, \\ promoting healing, caring, and advocacy \\ (Litchfield \& Jondorsdottir, 2008; Willis, \\ Grace \& Roy, 2008; Cowling, Smith \& \\ Watson, 2008)." \\ "innovative, transformative curriculum \\ that is outcomes-based to develop \\ competent, caring professional graduates."
}

Stated theoretical framework "...development of nursing as an autonomous, person-centred and scientifically based profession."

Aim of the program is to produce graduates who are safe, competent and confident practitioners able to engage globally and locally.

Produce graduate nurses as "knowledge workers and competent practitioners" through development of metacognitive skills where theory and practice are equally important and "meaningful learning can be achieved through experience, demonstration, contemplation and imagination." 


\begin{tabular}{ll}
\hline ID & $\begin{array}{l}\text { Nursing theory and/or educational } \\
\text { philosophy } 2007\end{array}$ \\
& facilitate health and wellness. At the \\
same time, issues such as risk, \\
consequences and best practice will all \\
be examined in order to ... fully engage \\
in effective health care."
\end{tabular}

U7 Educational philosophy:

The curriculum provides a University education which reaches a balance between having practitioners who are 'work-ready' and extending the professional skills of scholarship and development of practice. ...This is done through the philosophical premises of 'inquiry learning', 'scaffolding of supports', and the use of 'communities of practice'."

Inquiry-based learning instills in students "the capacity to respond to and initiate change, to develop lifelong learning skills and to work interprofessionally."

"Inquiry learning, with the idea of facilitating questioning about situation and context, rather than routinely a 'problem to be solved', speaks to nursing problems which are not linear and encompass complexities of social, emotional, cultural and resource issues. Risk, consequences and best practices will be examined in order to offer the nurse and client/patient information and options to fully engage in effective health care. The reflective practice element of inquiry learning allows for ambiguity that is inevitable in the search for solutions in the real-world practice of nursing"

"within courses, the material is scaffolded to give more didactic instruction in the beginning, ... before the students are asked to apply the skills and problem solve in a context dependant simulated scenario and then to perform the skill in the 'real' situation of clinical practice."

U8 Nursing philosophy:

"does not draw exclusively on any one nurse theorist's work but is eclectic in nature. We do use nurse theorist's work as it is applicable to the content and process of what is being taught."

\author{
Nursing theory and/or \\ educational philosophy 2014
}

Nursing is the central focus. "Central to this curriculum is the focus of nursing as a profession with a unique body of knowledge, which allows nurses to operate dynamically between autonomous, supervisory and collaborative roles to promote or restore optimal health to individuals, groups or communities. A foundation of knowledge and skills for practising nursing in a variety of settings is built from the wide influences which inform nursing knowledge including the behavioural and social sciences, biological and physical sciences, established nursing practice and the art of nursing which encompasses problem solving processes and reflective practice." ... "In keeping with a philosophy of nursing which acknowledges other ways of knowing in addition to the scientific model, this 'evidence' includes exploring and utilising additional sources for sound clinical judgments such as intuition, experience, context and authority."

Several nursing theories underpin the program "to develop attitudes and values such as collaboration, partnership and cultural safety" - for example "the work of Irihapeti and Ramsden on cultural safety threads through subjects from the first year of the course... Evidence-based practice is 


ID $\begin{aligned} & \text { Nursing theory and/or educational } \\ & \text { philosophy } 2007\end{aligned}$
Educational philosophy:
"The philosophy of the school is based
on the following values: social justice;
cultural sensitivity; autonomy and
independence; caring; adaptability;
quality; and integrity. The school
believes that the patient must be viewed
in an holistic manner. Nursing ... we
believe is based on three tenets.
- $\quad$ Diagnosis and treatment of the
patient's and family's responses to
health and illness throughout the
lifespan;
Interaction between the patient,
environment, health, and nursing:
and
Study of the trilogy of COMFORT
-SAFETY-CARING of patients and
families (Hayes 1995)."

"Our curriculum blends the basic and applied sciences that ground our knowledge with the art of nursing to produce a practical, competent nursing practitioner."

\section{Nursing philosophy:}

"has been developed around four interrelated themes; approaches to teaching and learning, research based practice, clinical skill acquisition and contextualised, integrated health care delivery. ... based on notions of lifelong learning with teaching, learning and enabling integral to nursing practice. ... a research - orientated approach to practice and encourages clinical skills to be developed in a systematic and evidence based manner. ... with particular emphasis on issues of culture, gender, ethnicity and race, ... focus on significant contemporary health problems. ... Identified as National Health Priority areas."

Educational philosophy:

"students will develop the necessary skills associated with self-directed learning to learn about approaches to practice relevant to other conditions and circumstances. Students will be required to gain experience in health promotion activities and management of acute and chronic illness in a variety of settings." "an emphasis on culture, gender,

\section{Nursing theory and/or \\ educational philosophy 2014}

another important influence in the curriculum incorporating the concepts of reflective practice, clinical judgment, clinical reasoning, consumer choice and the use of best available evidence"

Five design principles underpin the curriculum:

1. authentic, real world and relevant

2. constructive, sequential and interlinked

3. require students to use and engage with progressively higher order cognitive processes

4. all are aligned with each other and the desired learning outcome

5. provide challenge, interest and motivation to learn.
"High quality nursing care focused on the perspective of the patient and family, is enhanced by a deep knowledge of human bioscience and is based on evidence that demonstrates the nursing interventions that promote best practice. The course content therefore emphasises the patient -centred approach to care, scientific understanding of normal and abnormal pathology and adopts a sturdy research-orientated approach.

This approach encourages systematic development of clinical competence applying evidence-based learning, promotes the development of professional and disciplinary knowledge, and enhances the integration of theory, practice and clinical decision making skills. Overall the curriculum emphasises the practice-based nature of nursing, the diverse work of the nurse-patient relationship which may take place in various settings, the practice and responsive roles of nursing practice and the active role that clinical and academic educators must play to support effective learning and advance the profession." 


\begin{tabular}{|c|c|}
\hline ID & $\begin{array}{l}\text { Nursing theory and/or educational } \\
\text { philosophy } 2007\end{array}$ \\
\hline & $\begin{array}{l}\text { ethnicity and race in the developmental } \\
\text { and life-span approach to health and } \\
\text { illness." }\end{array}$ \\
\hline U11 & $\begin{array}{l}\text { Nursing Philosophy: } \\
\text { “... school staff met to consider our } \\
\text { goals and the desired results of the } \\
\text { curriculum and agreed that the } \\
\text { constructs: Professionalism, Nursing } \\
\text { Care and Inquiry represented the } \\
\text { underpinning ideas and ideals of what } \\
\text { we were trying to achieve through the } \\
\text { curriculum." } \\
\text { Educational philosophy: } \\
\text { Aligned curriculum as described by } \\
\text { Biggs (1999). There are four organising } \\
\text { themes in the curriculum: Nursing, } \\
\text { Human Bioscience, Contexts of Care, } \\
\text { Nursing Inquiry. "The underpinning of } \\
\text { the ... curriculum is 'what the student } \\
\text { does.' We agree with Shuell, that: If } \\
\text { students are to learn desired outcomes } \\
\text { in a reasonably effective manner, then } \\
\text { the teacher's fundamental task is to get } \\
\text { students to engage in learning activities } \\
\text { that are likely to result in their achieving } \\
\text { those outcomes ... It is helpful to } \\
\text { remember that what the student does is } \\
\text { actually more important in determining } \\
\text { what is learned than what the teacher } \\
\text { does (Shuell, 1986:411)." }\end{array}$ \\
\hline
\end{tabular}

U16 Not supplied

Nursing theory and/or

educational philosophy 2014

Three major themes provide framework for the curriculum:

1. professional identity

2. dynamics of being human

3. dynamics of practice

"Coherent, explicit philosophy of teaching and learning; problem/inquiry based, scenario based approach to teaching and learning throughout the curriculum; competency based approach to assessment; fundamental commitment to diversity of delivery and assessment; a core driving focus on nursing practice, in which supporting disciplines adapt to the needs of nursing"

Teaching \& Learning: Authentic, Engaging, Integrated, Interdisciplinary

\section{Philosophy and theoretical framework of the curriculum}

"Nursing is a practice based discipline... The philosophical basis ... centred on a belief in the centrality of practical knowing to nursing. In privileging the primacy of practice as something complex and profound, we position practical knowing in nursing as both a way of knowing and a kind of knowledge that both grounds abstract theoretical knowledge and is informed by this knowledge. We believe that, the primacy of practice is a more satisfactory characterisation of that reality nursing than distortions such as 'theory and practice': distinctions sustained through technical and rational understandings of nursing." "praxis is a pragmatic, context dependent and ethics orientated form of knowledge (Flyberg, 2001:56). Fundamental to this form of knowing is the capability for informed situational judgement, and a habitual 


\begin{tabular}{ll}
\hline ID Nursing theory and/or educational & $\begin{array}{l}\text { Nursing theory and/or } \\
\text { educational philosophy } 2014\end{array}$ \\
\hline philosophy 2007 & receptivity and self-awareness best described \\
as 'mindfulness.". & "Applying the principles of being and \\
knowing as outlined by Heidegger the & curriculum is designed to call the student \\
into a learning circle which involves an & iterative process of exposure to and \\
engagement with knowledge and its & application in nursing practice. The \\
hermeneutic process of interpretation is \\
circular, where understanding is sought \\
through a dynamic movement between the \\
part and the whole of narrative."
\end{tabular}

\section{Discussion}

The longstanding tension regarding the delineation of the "art and science" of care in nursing practice reflects, and potentially reinforces, perceptions of a hegemony supported by medical technicity and economic rationalisation. The actual discussion of "what is science" is rarely entered into at pre-registration level. A qualitative study undertaken as part of a doctoral thesis indicated that nurses deemed science content as foundational knowledge based in factual content, not science as a process for gaining knowledge. This factual knowledge was expected to support critical thinking and rationales for clinical practice to create a nurse who was termed by some to be a "bedside scientist" (Logan, 2008). Understanding the scientific process and the benefits of that understanding were delegated to research and evidence-based practice subjects. Experimental design and understanding limitations of results were deemed the realm of the stereotypical scientist who wore a white coat. Certainly, the distinction between technology as a product of science and science as a knowledge development process was not made. In fact, they were often confounded (Logan, 2008).

A student of Level 1 human bioscience stated upon returning from nursing practicum: I have seen a lot of terminology we have learnt in science ... it is nice to see the relevance and application of the uni work. This statement illustrates the challenge for service taught subjects to provide practice contexts particularly when more than one discipline group is represented in the student cohort. Yet the value of science to practice, as rated by students, is high (Birks, Cant, Al-Motlaq, $\&$ Jones, 2011). There has been recognition that students do not autonomously transfer knowledge between discrete subjects unless they are given a context for such transference (Minasian-Batmanian, et al., 2006). As a result, the separation of theory from practice such as foundational science content being separated from practice-based subjects, is thought to reinforce a theory-practice gap. Practice provides the opportunity for a nexus between discrete subjects to develop while students are experiencing practicum. It can be seen in the comparison between 2007 and 2014 that this nexus is being brought more prominently to the forefront of the curricula through simulations, case-based programs and inquiry based 
formats for teaching and learning. The increase of the integration of pathophysiology and pharmacology subjects into nursing subjects would also support a practice-theory knowledge nexus.

The 2014 U16 document deems the "theory-practice gap" a distortion of nursing practice in an attempt to reject the theory-practice gap concept through undertaking a course philosophy where "privileging the primacy of practice" dominates the curriculum. Further examination of Table 5, however, indicates the "science versus care" divide has not been entirely lost to nursing. For example, U5's 2007 documentation refer to "humanistic and scientific" aspects of nursing and have reinforced the "scientific" statement using "nursing is a scientifically based profession" in 2014. U9 in 2014 claims nursing requires scientific understanding and evidence based care that is enhanced by a "deep knowledge of bioscience" whereas such a strong statement is lacking in the 2007 documentation. U4 referred to nursing as an art and a science in 2007 but this reference has been lost from the 2014 curriculum. U8 stated in 2007 "our curriculum blends the basic and applied sciences that ground our knowledge with the art of nursing" yet this is not present in the recent document though the term 'evidence based practice' is given and deemed an "important influence." U1 and U11 have omitted the words "science" or "scientific" in either time period although practice is said to be evidence-based. Certainly, an emphasis on implementing established nursing theories as part of the curriculum is less evident than was apparent in the 2007 documents and a minimisation of the theorypractice gap is highlighted through increased use of education formats that provide practice situational contexts.

For the scientist teaching into applied health fields such as allied health and nursing professions, a challenge arises to provide situational context. As noted earlier in this discussion, it can be even more difficult in multidisciplinary cohorts. When interdisciplinary differences exist in practice philosophies and these differences are not clearly understood, then the challenges are further compounded for the scientist. Content determined directly from the supplied curricula provides minimal insight by listing the foundational aspects of body function relevant to practice but the context aspects of practice are not overtly expressed or prioritised. Individual subject curriculum documents usually outline an abstract or summary of the topics to be covered with a series of learning objectives provided. The entire subject outline may cover only two pages of a preregistration curriculum document. The challenge is therefore to determine the appropriate level of the detail and context from these documents. Several researchers have undertaken this challenge at various times (Jordan \& Hughes, 1998; Logan, 2008; Prowse \& Lyne, 2002; Wilkes \& Batts, 1998; Wilson, 1975) yet it remains a contested component for educational design.

Responses to a survey of 100 registered nurses suggested that nurses intuitively know the level of science content for practice and how it can best be taught (72\%) yet $41 \%$ indicated that they felt a nurse teaching fundamentals of science should also hold qualifications in a traditional science area (Logan, 2008). Nursing 
academics comprise only $35 \%$ of the lecturers teaching the bioscience subjects in New Zealand (Nicol, 2002) and in the UK only $15 \%$ of basic science lecturers had nursing qualifications (Wharrad, Allcock, \& Chapple, 1994). More recent data is not available for international or national programs. It may be possible to overcome the challenges through team teaching - nurses and scientists together, enabling perceived gaps to be bridged. Donald (2002), whose work outlines discipline specific differences within science fields, indicated that interaction facilitates the integration of scientific principles whilst enabling the understanding of relevance to specific areas of knowledge. This approach supports educational formats such as IBL and case based learning and may be ultimately evident in simulation-based assessments. In using a team-based approach the explicit understanding of foundational science content that practitioners may fail to recognise (Estabrooks et al., 2005; Titchen \& McGinley, 2004) may become more apparent to scientists and so better communicated to students. Curriculum design that makes practice - science theory links explicit requires effective nurse and scientist teamwork embedded within a pedagogy that recognises the links, strengths and weaknesses of both disciplines with respect to the totality that is patient care.

\section{Conclusion}

Despite representing approximately only one third of all courses offered by Australian Universities, the longitudinal comparison of the nine supplied nursing curriculum documents demonstrates a clear trend in the changes that have occurred. It is evident that although explicit science content, as designated by labels such as human bioscience, pathophysiology or pharmacology, has decreased, much of this content has been integrated into nursing subjects. It has become less conspicuous and less defined in newer curriculum documents. There is an increased undertaking by nursing higher education programs to incorporate case-based, inquiry based and simulation learning experiences for students that provide clear contexts for theoretical knowledge within practice. Further research independently evaluating full program designs in order to compare educational approaches for nursing practice would be beneficial. An exploration of how the concepts of science and foundational science content is incorporated into casebased and inquiry based frameworks would assist those who undertake teaching for health practice professions. Further, a study of the potential benefits of discipline team teaching upon learning for students in subjects where science is integrated might also elicit those linked practice concepts for dissemination and provide a clear indication of where science fits within curriculum.

\section{Acknowledgements}

The authors sincerely thank all those university departments who kindly supplied their curriculum documents for this review. The authors would also like to thank Dr. Kay Owens and Associate Professor Maree Simpson for reviewing early drafts of this paper. 


\section{References}

Akinsanya, J. A., \& Hayward, J. C. (1980). The biological sciences in nursing education: The contribution of bionursing. Nursing Times, 76, 427-432.

Andrew, S. (2002). The relationships among first year Bachelor of Nursing students. Unpublished doctoral thesis. University of Wollongong, Australia.

Andrew, S., Salamonson, Y., Weaver, R., Smith, A., O’Reilly, R., \& Taylor, C. (2008). Hate the course or hate to go: Semester differences in first year nursing attrition. Nurse Education Today, 28, 865-872. doi:10.1016/j.nedt.2007.12.007

ANMAC (2012). Registered Nurse Accreditation Standards 2012. Australian Nursing \& Midwifery Accreditation Council ANMAC. Retrieved from http://www.anmac.org.au/accreditation-standards

ANMC (2009). Australian Nurses and Midwives Council (ANMC) Accreditation Guidelines. Australia: National Nurse and Midwives Board (NNMB).

Arthur, H., \& Baumann, A. (1996). Nursing curriculum content, an innovative decisionmaking process to define priorities. Nurse Education Today, 16(1), 63-68. doi: 10.1016/S0260-6917(96)80095-5

Australian Qualifications Framework (AQF) Council for the Ministerial Council for Tertiary Education and Employment. (2011). Australian Qualifications Framework $(A Q F)$. South Australia: Australian Qualifications Framework Council for the Ministerial Council for Tertiary Education and Employment 2011.

Bebb, H., \& Pittam, G. (2004). Inquiry-based learning as a 'whole-curriculum approach': the experiences of first-year nursing students. Learning in Health and Social Care, 3(3), 141-153. doi: 10.1111/j.1473-6861.2004.00071.x

Biggs, J. (2003). Teaching for quality learning at university. What the student does. $\left(2^{\text {nd }}\right.$ ed.). New York: SRHE \& Open University Press.

Birks, M., Cant, R., Al-Motlaq, M., \& Jones, J. (2011). I don't want to become a scientist: Undergraduate nursing students' perceived value of course content. Australian Journal of Advanced Nursing, 28(4), 20-27. Retrieved from http://www.ajan.com.au/Vol28/28-4.pdf\#page=21

Bradley, E., Blackshaw, C., \& Nolan, P. (2006). Nurse lecturers' observations on aspects of nurse prescribing training. Nurse Education Today, 26(7), 538-544. doi:10.1016/j.nedt.2006.01.008

Brown, C., \& Seddon, J. (1996). The social body and the biomechanical body: Can they co-exist in nurse education? Journal of Advanced Nursing, 23(4), 651-656.

Davis, G. M. (2010). What is provided and what the registered nurse needs - Bioscience learning through the pre-registration curriculum. Nurse Education Today, 30(8), 707712. doi: $10.1016 /$ j.nedt.2010.01.008

Diekelmann, N. L., Ironside, P. M., \& Gunn, J. (2005). Recalling the curriculum revolution. Innovation with research. Nursing Education Perspectives, 26(2), 70-77.

Don, M. (2001). Science knowledge within a problem-based learning nursing course: a scientist's experience. Focus on Health Professional Education, 3(3), 1-9.

Donald, J. (2002). Learning to Think: Disciplinary Perspectives. San Francisco, CA: Jossey Bass. 
Dwyer, G. \& Higgs, J. (1999). Profiling health science students In: J. Higgs \& H. Edwards (Eds.). Educating Beginning Practitioners Challenges for Health Professional Education. (pp. 125-135). Oxford, UK: Butterworth-Heinemann.

Estabrooks, C. A., Rutakumwa, W., O’Leary, K. A., Profetto-McGrath, J., Milner, M., Levers, M., \& Scott-Findlay, S. (2005). Sources of practice knowledge among nurses. Qualitative Health Research, 15(4), 460-476. doi: 10.1177/1049732304273702

Forbes, H. (2000). Beliefs and learning approaches of undergraduate nursing students in a problem-based learning (PBL) environment. The Australian Electronic Journal of Nursing Education, 5(2), 1. Retrieved from http://scu.edu.au/schools/nhcp/aejne/archive/vol5-2/forbeshvol5_2.html

Friedel, J. M., \& Treagust, D. F. (2005). Learning bioscience in nursing education: Perceptions of intended and the prescribed curriculum. Learning in Health and Social Care, 4(4), 203-216. doi: 10.1111/j.1473-6861.2005.00104.x

Freshwater, D. (2000) Crosscurrents: against cultural narration in nursing. Journal of Advanced Nursing, 32(2), 481-484. doi: 10.1046/j.1365-2648.2000.01499.x

Gaynor, L. T., Gallasch, T., Yorkston, E., Stewart, S., Bogossian, F., Fairweather, C. ... Turner, C. (2007). The future nursing workforce in Australia: baseline data for a prospective study of the profile, attrition rates and graduate outcomes in a contemporary cohort of undergraduates. Australian Journal of Advanced Nursing, 25(2), 11-20.

Giddens, J. F., \& Brady, D. P. (2007). Rescuing nursing education from content saturation: The case for a concept-based curriculum. Journal of Nursing Education, 46(2), 65-69.

Harvey, V., \& McMurray, N. (1994). Self-efficacy: A means of identifying problems in nursing education and career progress. International Journal of Nursing Studies, 31(5), 471-485. doi: 10.1016/0020-7489(94)90017-5

Heath, P. (2002). National Review of Nursing Education: Our Duty of Care. A Final Report. Canberra, Australia: Commonwealth Department of Education, Science and Training (DEST).

Ironside, P. M. (2001). Creating a research base for nursing education: An interpretive review of conventional, critical, feminist, postmodern, and phenomenological pedagogies. Advances in Nursing Science, 23(3), 72-87.

Ironside, P. M. (2006). Using narrative pedagogy: learning and practising interpretative thinking. Journal of Advanced Nursing, 55(4), 478-486. doi: 10.1111/j.13652648.2006.03938.x

Jegede, O. J., \& Aikenhead, G. S. (1999) Transcending cultural borders: Implications for science teaching. Research in Science \& Technological Education, 17(1), 5-17. doi: $10.1080 / 0263514990170104$

Jordan, S., Davies, S., \& Green, B. (1999). The biosciences in the pre-registration nursing curriculum: staff and students' perceptions of difficulties and relevance. Nurse Education Today, 19, 215-226. doi:10.1016/S0260-6917(99)80007-0

Jordan, S., \& Hughes, D. (1998). Using bioscience knowledge in nursing: Actions, interactions and reactions. Journal of Advanced Nursing, 27(5), 1060-1068. doi: 10.1046/j.1365-2648.1998.00611.x 
Kocaman, G., Dicle, A., \& Ugur, A. (2009). Research brief: A longitudinal analysis of the self-directed learning readiness level of nursing students enrolled in a problem-based curriculum. Journal of Nursing Education, 48(5), 286-290. doi:10.9999/0148483420090416-09

Logan, P. A. (2008). Science in undergraduate nursing programmes: generating symbiotic praxis. (Unpublished doctoral thesis). Charles Sturt University, Australia.

Logan, P. A., \& Angel, L. (2011). Nursing as a scientific undertaking and the intersection with science in undergraduate studies: implications for nursing management. Journal of Nursing Management, 19, 407-417. doi:10.1111/j.1365-2834.2011.01247

Logan, P. A., Cox, J. E., \& Nielsen, S. (2013). Short online test and survey as an indicator of student risk in bioscience at a regional university. International Journal of Innovation in Science and Mathematics Education Special Edition, 21(3), 17-29. Retrieved from http://openjournals.library.usyd.edu.au/index.php/CAL/article/view/7197/7666

Manias, E., \& Bullock, S. (2002). The educational preparation of undergraduate nursing students in pharmacology: Clinical nurses' perceptions and experiences of graduate nurses' medication knowledge. International Journal of Nursing Studies, 39, 773-784. doi: 10.1016/S0020-7489(02)00008-1

McAllister, M. (2001). Principles for curriculum development in Australian nursing: An examination of the literature. Nurse Education Today, 21, 304-314. doi: 10.1054/nedt.2001.0562

McVicar, A. (2009). A post-registration solution to the 'bioscience problem'? British Journal of Nursing, 18(3), 149. doi: 10.12968/bjon.2009.18.3.39040

McVicar, A., Clancy, J., \& Mayes, N. (2010). An exploratory study of the application of biosciences in practice, and implications for pre-qualifying education. Nurse Education Today, 30(7), 615-622. doi:10.1016/j.nedt.2009.12.010

Minasian-Batmanian, L. C., Lingard, J., \& Prosser, M. (2006). Variation in student reflections on their conceptions of and approaches to learning biochemistry in a firstyear health sciences' service subject. International Journal of Science Education, 28(15), 1887-1904. doi: 10.1080/09500690600621274

Nicol, M. J., (2002). The teaching of genetics in New Zealand undergraduate nursing programmes. Nurse Education Today, 22, 401-408. doi:10.1054/nedt.2002.0744

O'Donnell, H. (2011). Expectations and voluntary attrition in nursing students. Nurse Education in Practice, 11, 54-63. doi: 10.1016/j.nepr.2010.08.002

Prowse, M. A., \& Heath, V. (2005). Working collaboratively in health care contexts: The influence of bioscientific knowledge on patient outcomes. Nurse Education Today, 25(2), 132-139. doi: 10.1016/j.nedt.2004.11.007

Prowse, M. A., \& Lyne, P.A. (2002). Revealing the contribution of bioscience based nursing knowledge to clinically effective patient care. Clinical Effectiveness in Nursing, 4(2), 67-74. doi: 10.1054/cein.2000.0105

Salamonson, Y., Andrew, S., \& Everett, B. (2009). Academic engagement and disengagement as predictors of performance in pathophysiology among nursing students. Contemporary Nurse, 32(1-2), 123-132.

Snelling, P. C., Lipscomb, M., Lockyer, L., Yates, S., \& Young, P. (2010). Time spent studying on a pre-registration nursing programme module: An exploratory study and 
implications for regulation. Nurse Education Today, 64(1), 49-59.

doi:10.1016/j.nedt.2010.01.010

Stockhausen, L. J. (2005). Learning to become a nurse: students' reflections on their clinical experiences. Australian Journal of Advanced Nursing, 22(3), 8-14.

Swenson, M. M., \& Sims, S. L. (2000). Toward a narrative-centered curriculum for nurse practitioners. Journal of Nursing Education, 39(3), 109-115.

Titchen, A., \& McGinley, M. (2004). Blending self-knowledge and professional knowledge in person-centred care. In J. Higgs, B. Richardson \& M.A. Dahlgren (Eds.), Developing Practice Knowledge for Health Professionals (pp. 107-126). London: Butterworth-Heinemann.

Thornton, T. (1997). Attitudes towards the relevance of biological, behavioural and social sciences in nursing education. Journal of Advanced Nursing, 26(1), 180-186. doi: 10.1046/j.1365-2648.1997.1997026180.x

Tomey, A. M., \& Alligood, M. R. (Eds.). (2006). Nursing theorists and their work (6th ed.). St. Louis, MO: Mosby Elsevier.

Turner, C., Davies, E., Beattie, H., Vickerstaff, J., \& Wilkinson, G. (2006). Developing an innovative undergraduate curriculum - responding to the 2002 National Review of Nursing Education in Australia. Collegian, 13(2), 7-14. doi: 10.1016/S13227696(08)60518-1

van de Mortel, T. F., \& Bird, J. L. (2010). Continuous curriculum review in a bachelor of nursing program: preventing curriculum drift and improving quality. Journal of Nursing Education, 49(10), 592-595. doi: 10.3928/01484834-20100730-05

Wells, S. H., Warelow, P. J., \& Jackson, K. L. (2009). Problem Based Learning (PBL): A conundrum. Contemporary Nurse, 33(2), 191-201.

Wharrad, H. J., Allcock, N., \& Chapple, M. (1994). A survey of the teaching and learning of biological sciences on undergraduate nursing courses. Nurse Education Today, 16(6), 436-442. doi: 10.1016/0260-6917(94)90004-3

Wilkes, L. M., \& Batts, J. E. (1992). Nurses' understanding of physical science in nursing practice. Nurse Education Today, 18(2), 125-132. doi: 10.1016/S02606917(98)80016-6

Wilson, K. (1975). A study of the biological sciences in relation to nursing. Edinburgh, UK: Churchill Livingstone.

Whyte, D. G., Madigan, V., \& Drinkwater, E. J. (2011). Predictors of academic performance of nursing and paramedic students in first year bioscience. Nurse Education Today, 31(8), 849-854. doi: 10.1016/j.nedt.2010.12.021

Copyright (C) 2014 Patricia A. Logan and Lyndall Angel 